\title{
Statins cholesterol lowering and mental health: a review
}

Pandelis Pazarlis*1, Konstantinos Katsigiannopoulos², Stavroula Bolimou ${ }^{2}$,

\author{
Aliki Ioakimidou², Georgios Papazisis², Gregory Xidopoulos², \\ Pavlos Vasiliadis², Aggelos Dampalis², Athanasios Milousis ${ }^{2}$ and \\ Christos Antonoglou ${ }^{3}$
}

Address: ${ }^{1}$ Panhellenic Association for Continual Medical Research (PACMeR) Section of Public-Health, Multicent, Thessaloniki, Greece, 2Panhellenic Association for Continual Medical Research (PACMeR) Section of Psychiatry, Multicentric, Greece and ${ }^{32}$ nd Department Of Internal Medicine, Demokritus University Of Thrace, Alexandroupoli, Greece

* Corresponding author

from International Society on Brain and Behaviour: 2nd International Congress on Brain and Behaviour Thessaloniki, Greece. 17-20 November 2005

Published: 28 February 2006

Annals of General Psychiatry 2006, 5(Suppl I):S25I doi:I0.1 I86/I744-859X-5-SI-S25 I

\section{Background}

Epidemiological and clinical studies have suggested that powerful cholesterol lowering may have adverse effects on mood and psychological well-being. Reports in the early 1990s showed that LDL cholesterol lowering might have an undesirable impact on mental health (possible increase of violence, accidents and suicide). As a result, the scientific interest is strongly focused on the effects of statins therapy on mental status (i.e. irritability, depressive symptoms, and anxiety). The aim of our study is to review the literature involving statins and mental health and to analyze it by time.

\section{Materials and methods}

Three medical libraries (MEDLINE, COCHRANE, ISI Web of Science) were systematically searched in order to investigate the cumulative randomized evidence on the possible existence of correlation between statin treatment and mental health. Three chronological periods were further defined for by-time analysis of medical literature: early 1990 s, late 1990 s and 2000s reports. We identified fortyfive peer reviewed related reports and only seven related randomized studies.

\section{Results}

In the early 1990s a meta-analysis raised concerns about a possible increase of deaths in groups receiving treatment for lowering serum cholesterol levels. This resulted in further investigation of the association between the reduction of cholesterol concentration and deaths or violent tendencies. In the late 1990s several double-blind rand- omized trials showed that there is no statistically significant effect of low cholesterol concentrations on the psychological well-being. At present, a strong hypothesis has been put forward about the effect of the statins themselves on some specific psychological parameters. This effect seems to be unrelated to cholesterol levels. Many randomized controlled studies came to the conclusion that there is a reduction of depressive symptoms, anxiety and hostility in patients treated with statins. The lipophilic statins, as opposed to all other cholesterol-lowering drugs, appeared primarily responsible for the observed effect on psychological well-being. A cholesterol-independent immunomodulatory mechanism has been postulated. Penetration of the blood-brain-barrier by the lipophilic molecule results in: inhibition of HMGCoA reductase, suppression of the Th1-type cytokines, interferon-gamma (IFN- $\gamma$ ) and interleukins IL-2 and IL12; promotion of the secretion of Th-2-type cytokines and IL-4 and IL-5 and IL-10; lowering of tryptophan availability and decreasing of serotonine levels. Whether statins improve tryptophan metabolism is worth being tested in more clinical trials.

\section{Discussion}

At present, statins are supposed to improve the psychological well-being and to reduce depressive symptoms, despite the early 1990s observations that statin treatment might be a risk factor for self-destructive behaviour even suicide. Individuals with current statin use may have a lower risk of developing depression, an effect that could be also explained by improved quality of life due to the 
decreased risk of cardiovascular events or higher health consciousness in patients receiving long-term treatment. It seems to be possible that an independent immunoregulatory statin effect is responsible for the alteration of the psychological well-being in treated patients. Further laboratory and clinical research, additional to meta-analysis of the existed randomised trials would be useful.

\section{References}

I. Young-Xu Y, Chan KA, Liao JK, Ravid S, Blatt CM: Long-term statin use and psychological well-being. J Am Coll Cardiol 2003, 42:690-697.

2. Stewart RA, Sharples KJ, North FM, Menkes DB, Baker J, Simes J: Long-term assessment of psychological well-being in a randomized placebo-controlled trial of cholesterol reduction with pravastatin. The LIPID Study Investigators. Arch Intern Med 2000, 160:3144-3152.

3. Seed M, Weir MR: Double-masked comparison of the quality of life of hypercholesterolemic men treated with simvastatin or pravastatin. International Quality of Life Multicenter Group. Clin Ther 1999, 21:1758-1770.

4. Muldoon MF, Manuck SB, Matthews KA: Lowering cholesterol concentrations and mortality: a quantitave review of primary prevention trials. BMJ 1990, 30 I:309-314.

Publish with Biomed Central and every scientist can read your work free of charge

"BioMed Central will be the most significant development for disseminating the results of biomedical research in our lifetime. "

Sir Paul Nurse, Cancer Research UK

Your research papers will be:

- available free of charge to the entire biomedical community

- peer reviewed and published immediately upon acceptance

- cited in PubMed and archived on PubMed Central

- yours - you keep the copyright

Submit your manuscript here:

http://www.biomedcentral.com/info/publishing_adv.asp 